\title{
DILEMAS ÉTICOS ORGANIZACIONAIS: OBSERVAÇÕES NO PROJETO SECRETARIADO EXECUTIVO EM DEBATE
}

\author{
L. S. Rocha' ${ }^{1}$ C. M. P. Barros ${ }^{2}$; J. S. Silva ${ }^{3}$; F. E. R. Silva ${ }^{4}$; L. F. S. Maciel ${ }^{5}$ \& A. V. S. Mendes ${ }^{6}$ \\ 1Bolsista e graduanda em Secretariado Executivo pela Universidade Federal do Ceará (UFC). E-mail: leticia.cdd@ gmail.com; 2Coordenadora do Núcleo de Estudos e \\ Pesquisas em Secretariado Executivo - NEPES. E-mail: conceicaompb@ufc.br; 3Coordenadora do Projeto de Extensão Secretariado em Debate. E- \\ mail: joelma.soares@ufc.br; 4Servidor técnico-administrativo da Universidade Federal do Ceará (UFC).E-mail: fedsonrsilva@ hotmail.com; 5Graduando em Secretariado \\ Executivo pela Universidade Federal do Ceará (UFC). Email: luizf2297@gmail.com; 6Graduando em Secretariado Executivo pela Universidade Federal do Ceará (UFC) \\ Email: arturavsm23@gmail.com.
}

Artigo submetido em setembro/2018

\section{RESUMO}

Este trabalho apresenta resultados de uma discussão acerca do tema "dilemas éticos no contexto profissional", realizada no Projeto de Extensão "Secretariado Executivo em Debate", desenvolvido pelo NEPES - Núcleo de Estudos e Pesquisas em Secretariado Executivo, da Universidade Federal do Ceará. Tem como objetivo geral analisar a percepção dos participantes do projeto sobre dilemas éticos no contexto profissional, tomando como bases a série americana Greys's Anatomy, a teoria de Sánchez Vázquez (2013), um artigo-reportagem da ICTS
(2013) e o Código de Ética do Secretariado (1989). Com abordagem qualitativa, por meio da análise fílmica, utilizou-se a análise compreensiva do discurso para intepretação dos dados coletados no debate. Observou-se entre os participantes uma percepção da ética associada aos Códigos e à punição, mas também uma diferenciação entre comportamento ético e comportamento moral. O estudo reforçou a importância de se debater ética, tanto na Universidade, como fora desta, afirmando a relevância da extensão universitária.

PALAVRAS-CHAVE: Ética. Secretariado Executivo. Extensão. Análise Fílmica.

\section{ORGANIZATIONAL ETHICAL DILEMMAS: OBSERVATIONS IN PROJECT "SECRETARIADO EXECUTIVO EM DEBATE”}

\begin{abstract}
This study presents the results of a discussion about "ethical dilemmas in the professional context", presented by the Extension Project "Secretariado Executivo em Debate", developed by NEPES Nucleus of Studies and Research in Executive Secretariat, in Universidade Federal do Ceará. As general objective, it aims to analyze the perception of the participants of the project on ethical dilemmas in the professional context, based on the series Greys's Anatomy, Sánchez Vázquez's theory (2013), an article-report of ICTS (2013) and the Secretariat Code
\end{abstract}

of Ethics (1989). With a qualitative approach, through film analysis, it was used the discourse comprehensive analysis to interpret the data collected. It was observed among the participants a perception of ethics associated with the Codes and punishment, but also a differentiation between ethical behavior and moral behavior. The study reinforced the importance of discussing ethics, both within and outside the University, affirming the relevance of university extension.

KEYWORDS: Ethics. Executive Secretariat. Extension. Film Analysis.

\section{INTRODUÇÃO}

O debate sobre ética, desde os tempos dos clássicos filósofos, tem se mostrado relevante, atual e urgente. Presente em todo o convívio social, desde os laços familiares até as 
redes de contatos profissionais, é o caráter reflexivo da ética que funciona como a base que fundamenta nossas noções de cidadania. O advento dos Códigos de Ética profissionais reforçou ainda mais a relevância que a ética assume em nossas vidas. Hoje já não é possível imaginar uma organização que não adote, ainda que de forma informal ou não institucionalizada, um determinado código de conduta, que dita, seja de forma positivada, seja culturalmente, certos modos e práticas de comportamento (organizacionais e mesmo sociais).

No contexto organizacional, Sousa Neta (2013, p 31) afirma que "a postura ética [...] permite a criação de uma imagem positiva diante da sociedade, auxiliando na consolidação [...] com atributos que transmitem credibilidade, segurança, qualidade e responsabilidade social”. O profissional de Secretariado Executivo também está inserido nessa realidade. Estando cada vez mais envolvido com os aspectos gerenciais e estratégicos tanto na esfera privada, como na instituição pública, os gestores buscam Secretários Executivos que adotem posturas éticas.

Nesse sentido, neste trabalho são apresentados os resultados de uma discussão acerca dessa temática, desenvolvido no projeto de extensão "Secretariado Executivo em Debate". Trata-se de um projeto de extensão desenvolvido no âmbito do Núcleo de Estudos e Pesquisas em Secretariado Executivo (NEPES) da Universidade Federal do Ceará (UFC).

O NEPES é um programa de Extensão do curso de Secretariado Executivo da UFC que surgiu em 2011 e visa contribuir para a tríade ensino, pesquisa e extensão, por meio da integração entre discentes, docentes e técnico-administrativos, por meio do desenvolvimento de estudos, pesquisas e ações extensionistas na área secretarial. Nessa perspectiva, emergiu, em 2013, a ação "Secretariado Executivo em Debate", que tem como objetivo principal debater teorias de diversas áreas do conhecimento relacionando-as ao Secretariado. Em 2018, um dos temas abordados foi "Dilemas éticos no contexto profissional", com a participação de estudantes do Curso de Secretariado Executivo, docentes e servidores técnico-administrativos.

A partir deste encontro, emergiu a questão norteadora desta pesquisa: o que a comunidade acadêmica compreende acerca da ética no contexto profissional? Seu objetivo geral é analisar a percepção dos participantes do projeto Secretariado Executivo em Debate sobre dilemas éticos no contexto profissional, utilizando uma abordagem qualitativa que inclui a utilização de filmes como pano de fundo para discussões teóricas. Buscou-se assim: a) conhecer as compreensões dos participantes acerca de ética; b) reconhecer percepções dos participantes sobre situações que envolvem o código de ética profissional; c) discutir dilemas éticos no ambiente profissional. 
Esta pesquisa encontra sua relevância na urgência em tratar-se o tema ética no contexto de formação de profissionais, um dos papéis da Universidade. Mas, para além desta função instrumental, o debate sobre ética também é relevante por apresentar um caráter substantivo fundamental para a construção cidadã, o que ultrapassa os muros da universidade.

\section{2 ÉTICA NO CONTEXTO ORGANIZACIONAL E NA PROFISSÃO SECRETARIAL}

\section{1 Ética e dilemas no contexto profissional}

A palavra "ética" encontra sua origem no termo grego ethos, ao qual se atribui, de uma forma geral, dois sentidos fundamentais. O primeiro significa "morada do homem", "lugar onde se habita". O segundo significa "modo de ser" ou "caráter", e é a acepção mais comumente adotada do termo (LÓPEZ ARANGUREN, 2003).

Assim, "para o filósofo grego Aristóteles, ethos é costume, hábito ou conjunto de valores culturais socializados de geração em geração através da tradição cultural" (KROHLING e KROHLING, 2013, p. 85). A ética é, portanto, um elemento social.

Para além das possibilidades etimológicas, o termo "ética" em si sofre mudança de significações ao longo do tempo. Novaes (1992) nos fala de uma "cisão radical" que a história do pensamento revela sobre os sentidos da ética.

Os filósofos gregos sempre subordinaram a ética às ideias de felicidade da vida presente e de soberano bem. [...] Hoje, a felicidade não é pensada mais nos termos da moral antiga, mas em termos de eficácia técnica, de consumo. Este é o ponto mais crítico da moral moderna. É como se houvesse um lento enfraquecimento da noção de ética e das conquistas do espírito com o avanço da técnica (NOVAES, 1992).

Dessa forma, como bem demonstra Rios (2001), a própria evolução sócio-histórica tratou de tornar a ética não mais o costume, mas a sua reflexão, o seu questionamento, os fundamentos e o alcance desse costume. Enquanto a moral é a conduta específica, a ética é o princípio que a vale. Ética e moral são, não raramente, tratadas como sinônimos ${ }^{1}$. No entanto, ética e moral se complementam, se inter-relacionam, mas moral seria um

sistema de normas, princípios e valores, segundo o qual são regulamentadas as relações mútuas entre os indivíduos ou entre estes e a comunidade, de tal maneira que estas normas [...] sejam acatadas livres e conscientemente, por uma convicção íntima, e não de uma maneira mecânica, externa ou impessoal (SÁNCHEZ VÁZQUEZ, 2013, p. 84)

\footnotetext{
${ }^{1}$ Tal confusão tem sua gênese mesmo na origem dos nomes, uma vez que a tradução latina para ethos foi mos ou mores (costume), ou moralis ou moralitas, que significam, respectivamente, moral (adjetivo) e moralidade (KROHLING e KROHLING, 2013).
} 
Assim, "ética e moral se relacionam, pois, como uma ciência específica e seu objeto" (SÁNCHEZ VÁZQUEZ, 2013, p. 24). Quando a ética aparece, já existe um contexto históricosocial repleto de práticas morais; a ética apenas busca determinar a justificativa, os princípios e as condições em que tais práticas se dão, inclusive suas mudanças. "A ética não cria a moral" (SÁNCHEZ VÁZQUEZ, 2013, p. 22). Dessa forma, a ética é teórica e reflexiva, ao passo que a moral é, sobremodo, prática. Enquanto essa é vivida e posta, aquela é pensada e filosofada. A ética é permanente, inerente aos homens; a moral é temporal ou transitória, o que hoje é considerado moral, talvez não o seja dentro de alguns anos ou décadas.

Por sua vez, Immanuel Kant, em sua "Fundamentação da Metafísica dos Costumes", aponta a ética como o agir a partir da boa vontade. Diferente do pensamento aristotélico que traz a felicidade como o único fim adequado à natureza humana, Kant traz a boa vontade como o meio para o agir ético. Para o autor, a felicidade não seria um bem em si próprio - pois o homem corrupto também buscará a felicidade, ainda que sua ação não seja permeada de boa vontade.

Percebe-se sinais da "cisão radical” apontada por Novaes (1992, p.8), quando a ideia de ética baseada em felicidade é substituída pelo "surgimento das normas éticas e dos preceitos a que se deve obedecer”. Em Kant, temos uma ética centrada na ideia do dever. Assim, Kant assinala que agir eticamente é agir com base na boa vontade, de acordo com a razão consciente - o que é correto, o dever.

Partindo dessa reflexão, discute-se o surgimento dos códigos de ética profissionais. De acordo com Alves et al. (2007), tais códigos têm o objetivo de regular as relações entre os membros de uma categoria profissional, "bem como entre ela e a sociedade, de maneira impositiva". Continua Alves et al. (2007), textualizando que "não é dada ao profissional a possibilidade de optar pela postura ética que ele julga mais adequada para resolver determinado dilema. Se divergir do código, será punido”. Mendes (2010, p. 34) reforça essa relação entre os códigos deontológicos e sua função punitiva quando aponta que "os Códigos de Ética surgem nas organizações com o objetivo de disciplinar a conduta do empregado e constituir instrumento de punição rápida às transgressões de conduta".

Os Códigos de Ética, dispositivos organizacionais baseados em uma racionalidade instrumental (RAMOS, 1989), parecem funcionar mais como Códigos de Conduta do que como Códigos de Ética, tomado o termo ética em sua acepção reflexiva. Tomando as organizações como um campo de estudo, verificamos a existência de uma constante tensão entre os elementos 
constitutivos de uma racionalidade instrumental e de uma racionalidade substantiva (RAMOS, 1989). Assim, podem configurar-se dilemas em que o racional vai de encontro ao emocional, o instrumental vai de encontro ao substantivo e as práticas vão de encontro aos valores pessoais.

A revista Exame publicou em 2013 uma pesquisa desenvolvida pela ICTS, organização que trabalha com consultoria, auditoria e serviços em gestão de riscos, que investigou 3.211 trabalhadores de 45 empresas privadas no Brasil para conhecer como reagiriam os sujeitos pesquisados diante de sete dilemas éticos específicos e diferentes entre si.

Entre os dilemas éticos apresentados, destacamos "denunciar um ato antiético cometido por um colega", "conviver com atos antiéticos", "adoção de 'atalho' antiético para atingir metas" e "usar informações confidenciais em benefício próprio" (ICTS, 2013). Sobre o primeiro dilema, $56 \%$ dos entrevistados da citada pesquisa disseram que somente denunciaram colegas se houvesse incentivo da empresa. Essa hesitação mostrou-se presente majoritariamente entre mulheres e entre funcionários de nível operacional (ICTS, 2013).

Sobre o dilema "conviver com atos antiéticos", um pouco mais que a metade dos pesquisados disse não ter restrições em conviver com a falta de ética. Esse índice é maior entre profissionais sem curso superior que recebem até 3 mil reais como salário e entre funcionários operacionais (ICTS, 2013). A ICTS (2013) também aponta que $48 \%$ dos respondentes escolheriam pegar um caminho mais curto, ainda que antiético, se fosse para cumprir objetivos estabelecidos. Essa constatação é maior entre os homens, principalmente entre aqueles maiores de 34 anos.

Quando se reporta ao dilema "usar informações confidenciais em benefício próprio", a pesquisa nos revela que essa atitude é mais propensa entre pessoas em cargos de gestão e com graduação (ICTS, 2013). De uma maneira geral, a pesquisa mostrou que $11 \%$ dos entrevistados não agem de acordo com os códigos de ética das empresas em que trabalham e que $69 \%$ agem circunstancialmente de forma ética ou antiética. Apenas $20 \%$ dos colaboradores pesquisados seguem à risca seus códigos de ética (ICTS, 2013). Observa-se que as questões de ética e dilemas significam desafios nas diversas áreas profissionais, incluindo-se a área secretarial, a qual é discutida a seguir.

\section{1 Ética no contexto secretarial}

Os conceitos de ética e moral são debatidos constantemente em inúmeras áreas 
profissionais, não sendo diferente para Secretários Executivos. Entre um dos deveres do profissional de Secretariado, descrito em seu Código de Ética ${ }^{2}$ profissional, encontra-se o de "direcionar seu comportamento profissional, sempre a bem da verdade, da moral e da ética" (BRASIL, 1989).

Passos (2012) compreende o ambiente organizacional como permeado por conflitos, por choques entre interesses individuais e, muitas vezes, entre esses e o da própria instituição, de modo que a ética servirá para regular essas situações. Tal dado nos leva a refletir sobre o papel do profissional como praticante e regulador de condutas consideradas éticas. Aplicandose ao profissional de Secretariado, que de acordo com as Resoluções do IV Fórum Nacional de Debates sobre Competências Profissionais promovido pela Federação Nacional das Secretárias e Secretários - FENASSEC (2008), é um profissional de nível estratégico, ser ético é elementochave para a sua atuação.

Durante (2012) coloca a ética secretarial como parte das competências comportamentais e relacionais do profissional, sendo uma das competências que "focalizam o aprender a [..] conviver com os outros, num clima propenso ao desenvolvimento de todos". Além disso, denota-se a importância do profissional de Secretariado ter conhecimento de seu Código, o que é, inclusive, orientação de formação para os cursos de Secretariado, conforme preconiza o artigo 18 do próprio Código: "Cabe aos Secretários docentes informar, esclarecer e orientar os estudantes, quanto aos princípios e normas contidas neste Código" (BRASIL, 1989).

Outro aspecto presente no cotidiano do profissional de Secretariado é o sigilo. Tal aspecto mereceu abordagem em dois artigos do Código, quais sejam o artigo 6 - "A Secretária e o Secretário, no exercício de sua profissão, deve guardar absoluto sigilo sobre assuntos e documentos que lhe são confiado", e o artigo $7^{\circ}$ - "É vedado ao Profissional assinar documentos que possam resultar no comprometimento da dignidade profissional da categoria" (BRASIL, 1989). Nesse sentido, Reis (2011, p. 91) corrobora com esse pensamento ao apontar que "no contexto do trabalho do secretário, o sigilo é fundamental para a conquista da confiança e o vínculo entre o profissional, seus superiores e a organização".

\section{MATERIAIS E MÉTODOS}

\footnotetext{
${ }^{2}$ O Código de Ética do profissional de Secretariado traz como objetivo "fixar normas de procedimentos dos Profissionais quando no exercício de sua profissão, regulando-lhes as relações com a própria categoria, com os poderes públicos e com a sociedade" (BRASIL, 1989).
} 
O presente trabalho, de cunho qualitativo (CRESWELL, 2010) e descritivo (ANDRADE, 2010), é o resultado de uma discussão realizada no projeto extensionista "Secretariado Executivo em Debate", como parte do programa de extensão NEPES, utilizandose como metodologia a análise fílmica. Participaram do debate estudantes de Secretariado Executivo, docentes e servidores técnico-administrativos, todos da UFC.

A utilização de filmes para estudo de teorias traz uma proposta inovadora no que diz respeito às metodologias de pesquisa, já que sua didática se torna muito mais acessível aos participantes da pesquisa. Em relação a suas especificidades, a linguagem fílmica para Machado e Matos (2012) está inclusa no campo do estudo observacional, que tem como característica fazer o detalhamento de comportamentos ou atividades, sendo dividida em um estudo direto ou indireto. $\mathrm{O}$ direto ocorre em tempo real, no qual o pesquisador acompanha o acontecimento do fato, já o indireto é realizado por meio de dados documentados, como, por exemplo, os filmes.

Assim, para aplicação da metodologia, foram seguidas as etapas de investigação e aplicação propostas por Machado e Matos (2012), a saber: a) construção da questão ou objetivo de pesquisa: foi realizada reunião de planejamento do encontro onde foram definidos o tema, a questão de pesquisa e os objetivos. b) busca e seleção da fonte de dados narrativos: no segundo momento, os pesquisadores analisaram os filmes que poderiam contribuir para o alcance dos objetivos; c) decupagem dos dados (cenas e falas): nesta etapa foram feitas a seleção das cenas que correspondiam aos objetivos definidos e que seriam analisadas durante o encontro; d) fundamentação e interpretação dos dados; e) produção do relatório final.

Dessa forma, para a análise fílmica foi escolhido o $13^{\circ}$ episódio da $5^{\mathrm{a}}$ temporada da série americana Grey's Anatomy, que figura situações de dilema ético dentro de uma organização hospitalar. Como referência teórica para discussão, adotou-se o texto Ética, de Sánchez Vázquez (2013), o artigo-reportagem “7 dilemas éticos e como os profissionais reagem a eles", da ICTS (2013), publicado pela revista de negócios e economia Exame, e o Código de Ética do Secretariado (BRASIL, 1989). Foi solicitado que os participantes assistissem ao episódio proposto e lessem as referências teóricas antes do debate.

Para a coleta das informações foi utilizado um roteiro que serviu de guia para o debate focalizando os objetivos do estudo. Tratou-se de um roteiro semiaberto, com algumas perguntas previamente estruturadas, mas deixando espaço para outras questões que surgissem no decorrer do debate. A análise e a interpretação dos dados foram realizadas por meio da técnica de análise 
compreensiva do discurso (KAUFMANN, 2013). Primeiramente, realizou-se a transcrição das falas gravadas dos participantes do debate. Em seguida foram selecionados os discursos mais relevantes para a pesquisa. Posteriormente utilizou-se uma ficha de escuta/interpretação adaptada de Barros (2017) para realizar associações entre os discursos dos presentes e os aspectos teóricos tomados como base para a pesquisa. Os resultados do trabalho são expostos na próxima seção.

\section{RESULTADOS E DISCUSSÕES}

A discussão no encontro, apresentada nesta seção, iniciou-se com a provocação “As pessoas são éticas por medo de punição?" (DISCENTE 1). De acordo com o Discente 2, "em parte". Para o discente, “é natural do ser humano, de certa forma, querer se beneficiar de determinadas situações". Ainda, o Discente 2 afirma que é o "medo do que pode acontecer" que leva as pessoas a adotarem uma postura ética. O discente relata que para frenar esse "instinto", "você tem um código [...] que vai te dizer o que você não pode fazer e que se você fizer, você está sujeito a determinadas punições. Isso impede você de seguir adiante" (DISCENTE 2).

Esse discurso reforça a ideia dos códigos de ética enquanto instrumentos impeditivos de posturas antiéticas e de caráter punitivo (MENDES, 2010). Em contraponto, podemos citar o texto de Platão, Críton ou o Dever. Nesta obra, Platão mostra um diálogo entre seu mestre, Sócrates e Críton. Sócrates encontra-se preso e Críton lhe apresenta uma proposta de fuga. Inicia-se, então, uma conversa sobre o valor desta possível ação, ao que Sócrates conclui e convence seu amigo a não realizar o plano. Sócrates toma essa decisão a partir do momento em que pensa nas consequências dessa ação para a sociedade, entre eles seus seguidores. Aqui, o homem ético é aquele que age pensando não no seu próprio bem, mas no bem comum (PLATÃO, 1993).

Em resposta à indagação sobre "já terem tido medo de tomar alguma atitude pensando que poderiam perder o emprego" (DISCENTE 1), a Discente 3 explanou que "isso depende muito da hierarquia na empresa". Para a discente, "geralmente a pessoa pode se sentir pressionada", no caso de ocupar um cargo de posição hierárquica inferior àquele ocupado por alguém que cometeu uma transgressão ética. "Ela recua para não tomar determinadas decisões para que ela não seja prejudicada”, continua a Discente 3 , fazendo alusão a uma possível atitude 
de denúncia do ato antiético.

Nesse sentido, fica clara a relação estabelecida entre hierarquia, poder e ética. Denotase do discurso da Discente 2 uma situação em que, por motivos de necessidade financeira, um funcionário de nível hierárquico inferior deixa passar atos antiéticos de funcionários que atuem como seus chefes, supervisores ou gestores. Tal relação também é apontada pela pesquisa realizada pela ICTS (2013), que mostra que a maior parte dos funcionários que hesitariam em denunciar atos antiéticos por parte de um colega encontra-se no nível operacional. Da mesma forma, também está no nível operacional a maior parcela de funcionários que não apresenta restrições em conviver com atos antiéticos (ICTS, 2013).

Assim, o discurso da discente, ao qual houve certo grau de concordância por parte da maioria dos participantes, no sentido de afirmarem ser uma situação comum, analisada juntamente aos dados da pesquisa da ICTS (2013), dão sinais de traços culturais organizacionais em que a falta de ética parece ser elemento ordinário nas relações desenvolvidas entre nível operacional e nível tático e estratégico. Para Daft (2006), a promoção do comportamento ético no âmbito profissional depende da inserção da ética na cultura da organização. No episódio da série utilizada como recurso para o debate, é comum cenas em que médicos em posição de chefia, tais como chefe de residente e cirurgião-chefe, não apenas adotam posturas antiéticas, como reconhecem tal prática. Foi apontado pelos participantes do debate, por exemplo, o fato da chefe dos residentes ter ponderado sobre salvar a vida de um paciente em detrimento da vida do outro, quando a postura esperada de um médico é fazer tudo ao seu alcance para salvar a vida de qualquer pessoa, independente de julgamentos pessoais. A mesma chefe adota durante outros episódios da série, conforme apontado pela Discente 3, um discurso que reforça a separação entre a postura profissional e a relação afetiva médico-paciente. No entanto, durante o episódio em questão, a médica não consegue permanecer dentro desse discurso.

Da mesma forma, foi apontado que o médico que ocupa o cargo de cirurgião-chefe ultrapassou o limite ético da relação médico-paciente. No episódio em tela, o médico insiste de maneira desrespeitosa com a viúva de um paciente morto para que ela aceite doar os seus órgãos. Ainda que seja tomada como uma causa nobre, denota-se do episódio a falta de tratamento do cirurgião-chefe para com a viúva. O próprio médico, ao final do episódio, assume ter "ultrapassado a linha". Pode-se estabelecer uma relação com um dos dilemas éticos apresentado pela pesquisa da ICTS (2013), que aborda a tomada de "atalhos" antiéticos para se atingir uma meta. Em referida pesquisa, $48 \%$ dos respondentes afirmaram que escolheriam 
pegar caminhos mais curtos, ainda que antiéticos, se precisassem cumprir objetivos estabelecidos.

Em resposta à colocação da Discente 3, a Docente 1 fala sobre uma certa "flexibilidade ética". De acordo com a discente, "não dá pra ser ético na circunstância A, sem ser ético na circunstância B". Ainda, complementa referindo-se a essa "flexibilidade ética" como algo que “cria um moral na sociedade, que nos move, e isso vai para a ética, que é a ação que a gente desenvolve".

Em seu discurso, a Docente 1 traz a moral como antecessora à ética, o que é corroborado por Sánchez Vázquez (2013), ao afirmar que quando a ética aparece, já existe um contexto histórico-social repleto de práticas morais. "A ética não cria a moral", nos explica Sánchez Vázquez (2013, p. 22). Entretanto, a ética é trazida pelo autor como uma reflexão, em contraponto à moral, que ele aborda como sendo uma ação. Em relação às práticas morais (ação moral), a ética apenas busca determinar a justificativa, os princípios e as condições em que tais práticas se dão, inclusive suas mudanças (reflexão ética).

Ainda no contexto hierarquia-ética, a Docente 2 contrapõe ao afirmar que

Esse caos que nós estamos vivendo hoje no nosso país, a maioria das pessoas, pelo menos as que estão na mídia, não são pessoas de nível hierárquico baixo. Muito pelo contrário: são pessoas que não sofreram pressão, elas muitas vezes [são as que] pressionaram. E então não havia ninguém acima deles, dos pobres dos nossos governantes, que tenham sofrido pressão para terem atitudes e estarem envolvidos em escândalos altamente antiéticos (DOCENTE 2).

Nesse sentido, podemos apontar também a pesquisa da ICTS (2013), quando demonstra que a maior propensão a se aproveitar de informações confidenciais para benefício próprio parte de profissionais que ocupam cargos de gestão e que possuem graduação. Tais profisssionais têm acesso à informações que, muitas vezes, não chegam, ou chegam apenas parcialmente, ao nível operacional. Ainda, são cargos diretamente ligados à gestão financeira e de recursos humanos e que concentram grande poder de tomada de decisões.

Para Daft (2006), as lideranças dos níveis hierárquicos superiores são responsáveis pela criação e manutenção da uma cultura que enfatize cotidianamente a importância da conduta ética para todos os funcionários. Como afirma Schein (2009), os líderes de organizações estão diretamente envolvidos no processo de criação, fixação e mudança da cultura organizacional. Essa mudança organizacional não é viabilizada em um ambiente em que os próprios gestores praticam atos antiéticos.

A Docente 2 discursa também no sentido de que é preciso "não confundir o que é ética com o que é valor pessoal", além de estabelecer uma diferença entre o comportamento ético, 
segundo a qual "sempre existirá", e o comportamento moral que, explica a docente, "é aquilo que eu decido que eu vou fazer e não tem código de ética no mundo que vai me dizer que eu não vou agir daquele jeito". A Docente 2 continua, dizendo que o comportamento moral "é uma decisão pessoal minha, de acordo com os meus valores, com aquilo que eu acredito".

À luz de Reale (2006, apud SILVA 2013), os valores estão condicionados tanto à percepção de vida como às regras sociais e oficiais, às quais o indivíduo está subordinado. “Todas as questões normativas são subjugadas ao contexto pessoal e vincula-se diretamente à percepção do sujeito perante o objeto, sem relação com qualquer conceito" (SILVA, 2013).

Em seguida, os participantes foram provocados a identificar transgressões e dilemas éticos na série utilizada como recurso de debate. Foram relatados, principalmente, a tensão provocada entre julgamentos pessoais e decisões profissionais, a ação pautada por valores pessoais ou por normas positivadas em códigos de conduta, a conivência com atos antiéticos e o desrespeito à hierarquia.

Nesse sentido, a Discente 4 citou os artigos $8^{\circ}$, inciso 4 do Código de Ética do Secretariado, que versa que "Compete às Secretárias e Secretários: [...] estabelecer um clima de respeito à hierarquia com liderança e competência", bem como o artigo $9^{\circ}$, inciso 3 , que traz que "É vedado aos profissionais [de Secretariado]: [...] ser, em função de seu espírito de solidariedade, conivente com erro, contravenção penal ou infração a este Código de Ética" (BRASIL, 1989).

A Docente 1 ressaltou a importância do tema debatido, afirmando que o "debate tem que estar presente nas universidades, escolas, nas disciplinas de sociologia, de filosofia, porque a gente precisa fortalecer uma mentalidade $[\ldots] "$.

Tal discurso encontra fundamento na própria natureza da ação extensionista. De acordo com a como bem expressa a Política Nacional de Extensão Universitária (FORPROEX, 2012, p.17), a extensão é:

O instrumento por excelência de inter-relação da Universidade com a sociedade, de oxigenação da própria Universidade, de democratização do conhecimento acadêmico, assim como de (re)produção desse conhecimento por meio da troca de saberes com as comunidades.

Assim, abrir o debate sobre ética no contexto organizacional para a comunidade acadêmica, mas também para a comunidade de forma geral, concorda com os elementos constitutivos da extensão (FORPROEX, 1987), quais sejam: processo educativo, cultural e científico; relação transformadora universidade-sociedade; processo dialético de teoria/prática; visão integrada do social; oportunidade de elaboração da práxis de um conhecimento 
acadêmico; troca de saberes sistematizados, acadêmico e popular; conhecimento da realidade nacional e regional; democratização do conhecimento acadêmico; e efetiva participação da comunidade na Universidade.

\section{CONCLUSÃO}

Os resultados demonstram que a noção de ética enquanto campo de reflexão, diferente da moral - campo das práticas, não é unânime no grupo em questão. Apesar de ser reconhecido pelos participantes que a moral antecede a ética, uma vez que a existências de práxis individuais e coletivas antecede a sua ponderação, ainda se confunde a ética como uma ação, e não como a ciência de uma ação - a moral.

Percebeu-se, nos relatos do grupo participante, a relação entre ética e os códigos de ética, estes sendo encarados como instrumentos punitivos para ações transgressoras, o que mais os aproxima de códigos de conduta, com normas positivadas, do que de ferramentas de reflexão sobre o comportamento organizacional. Essa percepção pode ser explicada, em parte, pela abordagem mais instrumentalista que filosófica dada ao tema nesta pesquisa, quando se pretendeu discuti-lo no contexto profissional.

Observou-se, por meio dos discursos, um alerta para uma cultura organizacional em que a ética está estritamente ligada às relações de poder dentro das organizações, traduzidas em elementos como hierarquia, cargo que se ocupa e grau de instrução. Ainda que tenham sido demonstrados exemplos de pessoas em cargos de gestão cometendo atos antiéticos, ainda é comum tratar a necessidade de se manter empregado, por questões econômicas, como uma explicação para o fato de omitir-se ou ser conivente diante de transgressões éticas. Infere-se que a diferenciação entre comportamento ético e comportamento moral foi absorvida pelo grupo, tendo sido explanada no próprio discurso de alguns participantes, além de ser um ponto do referencial teórico lido anteriormente pelos participantes.

Nesse contexto, evidencia-se a importância da promoção de debates sobre ética, não apenas no contexto profissional, mas, a título de sugestão, também no contexto docente-aluno, servidor-sociedade, e políticas universitárias-comunidade. Sendo a ética um fator fundador da noção de cidadania, é urgente que esse debate também ganhe corpo fora dos locais de formação, devendo assumir um lugar comum na fala de qualquer membro da sociedade.

Acredita-se que esta pesquisa pôde reforçar o caráter de relevância social das 
atividades de extensão. Diante de um contexto político que tentar dirimir o impacto social das universidades públicas, acredita-se que este trabalho tenha contribuído para demonstrar o papel social da universidade, que alcança a comunidade por meio de sua extensão.

\section{REFERÊNCIAS}

ANDRADE, Maria Margarida de. Introdução à metodologia do trabalho científico: elaboração de trabalhos na graduação. 10. ed. São Paulo: Atlas, 2010

ALVES, Francisco José dos Santos. WEFFORT, Elionor Farah Jreige. LISBOA, Nahor Plácido. ANTUNES, Maria Thereza Pompa. Um estudo empírico sobre a importância do Código de Ética Profissional para o contabilista. Revista de Contabilidade e Finanças da USP. Edição 30 anos de Doutorado, p. 58-68, jun. 2007. Disponível em: < http://www.revistas.usp.br/rcf/article/view/34224/36956>. Acesso em: 29 ago 2018.

ARISTÓTELES. A Política. São Paulo: Atena Editora, [1957?].

BARROS, Conceição de Maria Pinheiro. O lugar do educando (Outro) na atuação e formação do educador bacharel áltero (Eu). 2017. 316f.Tese (Doutorado em Educação) Universidade Estadual do Ceará, Fortaleza, 2017.

BRASIL. Código de ética do profissional de secretariado. 1989. Disponível em: <https://www.fenassec.com.br/b_osecretariado_codigo_etica.html>. Acesso em: 28 jun. 2018.

CRESWELL, John W. Projeto de Pesquisa: Métodos Qualitativo, Quantitativo e Misto. 3 ed. Porto Alegre: Artmed, 2010.

DAFT, Richard L. Organizações, teorias e projetos. São Paulo: Thomson Learning, 2006.

DURANTE, Daniela Giareta. Tópicos Especiais em Técnicas de Secretariado. Curitiba: IESDE Brasil, 2012.

FENASSEC. Resoluções do IV Fórum Nacional de Debates sobre Competências Profissionais: níveis de atuação, 2008. Disponível em: <www.fenassec.com.br/resolucoes_4oforum.doc.> Acesso em: 27 ago. 2018.

FORPROEX. Fórum de Pró-Reitores de Extensão das Universidades Públicas Brasileiras. Conceito de extensão, institucionalização e financiamento. I Encontro de Pró-Reitores de Extensão das Universidades Públicas Brasileiras. Brasília. 1987. Disponível em: $<$ https://www.ufmg.br/proex/renex/images/documentos/1987-I-Encontro-Nacional-doFORPROEX.pdf $>$. Acesso em 28 jun. 18.

FORPROEX. Fórum de Pró-Reitores de Extensão das Universidades Públicas Brasileiras. Política Nacional de Extensão Universitária. Coleção Extensão Universitária. Manaus: AM. 2012. Disponível em: <https://www.ufmg.br/proex/renex/images/documentos/Pol\%C3\%ADtica-Nacional-deExtens\%C3\%A3o-Universit\%C3\%A1ria-e-book.pdf>. Acesso em 28 jun. 2018. 
ICTS. 7 dilemas éticos e como os profissionais reagem a eles. Revista Exame. São Paulo, 14 jun. 2013. Disponível em: < https://exame.abril.com.br/carreira/7-dilemas-eticos-e-como-osprofissionais-reagem-a-eles/>. Acesso em: 28 jun. 2018.

KANT, Immanuel. Fundamentação da Metafísica dos Costumes e Outros Escritos. São Paulo: Martin Claret, 2005.

KAUFMANN, Jean-Claude. A entrevista compreensiva: uma proposta para pesquisa de campo. Petrópolis, RJ: Vozes, 2013.

KROHLING, Aloisio; KROHLING, Beatriz Stella Martins. Ética rizomática e teoria crítica do direito internacional dos direitos humanos. Revista de Estudos Constitucionais,

Hermenêutica e Teoria do Direito, São Leopoldo, v. 5, n. 1, p.82-92, jun. 2013. Disponível em: <http://revistas.unisinos.br/index.php/RECHTD/article/view/rechtd.2013.51.09>. Acesso em: 02 ago. 2018

LÓPEZ ARANGUREN, José Luis. La ética y su etimología. Arbor, v. 174, n. 687-688, p.591-606, 30 abr. 2003. Departamento de Publicaciones del CSIC. Disponível em: <http://dx.doi.org/10.3989/arbor.2003.i687-688.660>. Acesso em 21 ago. 2018.

MACHADO, Diego de Queiroz. MATOS, Fátima Regina Ney. (Orgs.). Estudos observacionais em linguagem fílmica. Curitiba: Editora CRV, 2012.

MENDES, Annita Valléria Calmon. Ética na administração pública federal: a implementação de comissões de ética setoriais - entre o desafio e a oportunidade de mudar o modelo de gestão. Brasília: Funag, 2010.

NOVAES, Adauto. Cenários. In: NOVAES, Adauto (Org.). Ética. São Paulo: Companhia das Letras, 1992

PASSOS, Elizete. Ética nas Organizações. São Paulo: Editora Atlas, 2012.

PLATÃO. Êutrifon, Apologia de Sócrates, Críton. Lisboa: Imprensa Nacional, Casa da Moeda, 1993.

RAMOS, Alberto Guerreiro. A nova ciência das organizações: uma reconceituação das riquezas das nações. 2 ed. Rio de Janeiro: Editora da Fundação Getúlio Vargas, 1989.

REIS, Jamili Paulo Kury dos. A ética profissional do secretário executivo e sua relação com a ética de João Calvino: uma aproximação. Dissertação (mestrado em Ciências da Religião) - Universidade Presbiteriana Mackenzie, São Paulo, 2011.

RIOS, Terezinha Azerêdo. Ética e competência. 10 ed. São Paulo: Cortez, 2001. (Coleção Questões da Nossa Época).

SÁNCHEZ VÁZQUEZ, Adolfo. Ética. 35 ed. Rio de Janeiro: Civilização Brasileira, 2013. 
SCHEIN, Edgar H.. Cultura organizacional e liderança. São Paulo: Atlas, 2009.

SILVA, Joelma Soares da. A relação entre os valores pessoais e as concepções de deficiência: um estudo com discentes de Administração. Dissertação (mestrado) Universidade Estadual do Ceará, Centro de Estudos Sociais Aplicados, Mestrado Acadêmico em Administração, Fortaleza, 2013.

SOUSA NETA, Gilvanira. Concepções éticas do profissional de Secretariado Executivo. 2013. 59f. Monografia (graduação) - Universidade Federal do Ceará, Faculdade de Economia, Administração, Atuária e Contabilidade, Curso de Secretariado Executivo, Fortaleza, 2013. 